Research Article

\section{Impact of amitriptyline on learning and memory}

\author{
Mfem $\mathrm{CC}^{1}$ and Seriki SA ${ }^{2 *}$ \\ 1Department of Physiology, College of Medical Sciences, University of Calabar, Calabar, Nigeria \\ ${ }^{2}$ Department of Physiology, College of Medical Sciences, Edo State University, Uzairue, Nigeria
}

\section{Summary}

Background/aim: Amitriptyline belongs to class of known as tricycline antidepresant (TCA) that is being used to treat anxiety and depressive states. It may help improve mood and feelings of well-being, relieve anxiety and tension, help to improve sleep and increase energy level. The study investigated the effect of amitriptyline on learning and memory using eighteen (18) healthy Swiss mice of both sexes weighing $16-25 \mathrm{~g}$.

Method: The animals were divided into three (3) groups consisting of six (6) animals each. Group 1 served as the control group, Group 2 was administered with amitriptyline at a dose of $3 \mathrm{mg} / \mathrm{kg}$ body weight dissolved in $3 \mathrm{mls}$ of distilled water, and used to test for learning, while Group three was also given similar administration like Group 2, but used to test for memory. All the animals were tested for learning and memory performance using Novel object recognition task and Morris water maze test.

Results: The results obtained from the Novel object recognition task showed that there was a significant decrease $(p<0.05)$ in total object approach in acquisition trial of amitriptyline treated group when compared to the acquisition trial of the control group. There was a significant decrease $(p<0.05)$ in retention trial of amitriptyline group when compared to retention trial in the control group. There was a significant decrease $(p<0.05)$ in total duration exploring objects in acquisition trial of amitriptyline treated group when compared to the acquisition trial of the control group. There was a significant increase $(p<0.05)$ in total duration exploring objects in retention trial of amitriptyline treated group when compared to the retention trial of the control group. There was a significant decrease $(p<0.05)$ in the index of habituation of amitriptyline treated group when compared to the control group. The index of discrimination showed a significant increase $(p<0.05)$ in amitriptyline treated group when compared to the control group and a significant decrease $(p<0.05)$ in amitriptyline group when compared to the control group. In the Morris water maze test, Day $1-3$ were for acquisition training, day $4-6$ reversal training, day 7 the probe trial day and day 8 the visible platform day. During acquisition training in the Morris water maze test, there was no significant difference in Swim latencies in day 1 and 2 . However in day 3, there was a significant increase $(p<0.05)$ in swim latency of group compared to control group and a significant decrease $(p<0.05)$ in swim latency of amitriptyline treated group compared to the control group. During reversal training in day 1, 2 and 3, there was no significant difference in swim latency among the three groups. Results for the retention quadrant in the probe trials showed a significant decrease $(p<0.01)$ in amitriptyline group when compared to the control group.

Conclusion: Results suggest that amitriptyline impairs learning and memory functions.

\section{More Information}

*Address for Correspondence: Seriki SA, Department of Physiology, College of Medical Sciences, Edo State University, Uzairue, Nigeria, Tel:+2348036041121; Email: seriki.adinoyi@gmail.com

Submitted: March 25, 2021

Approved: April 12, 2021

Published: April 14, 2021

How to cite this article: Mfem CC, Seriki SA. Impact of amitriptyline on learning and memory. Insights Depress Anxiety. 2021; 5: 009-015.

DOI: 10.29328/journal.ida.1001025

Copyright: @ 2021 Mfem CC, et al. This is an open access article distributed under the Creative Commons Attribution License, which permits unrestricted use, distribution, and reproduction in any medium, provided the original work is properly cited.

Keywords: Amitriptyline; Learning and memory; Antidepressant; Sleep

Check for updates

OPEN ACCESS

\section{Introduction}

Learning is one of the most important mental functions of humans. It is an adopted change in individual behavior resulting from experience. It relies on acquisition of different kinds of knowledge supported by perceived information. The mechanisms of learning and remembering seem to depend on relatively enduring changes in the nervous system. Its goal is the increasing of individual and group experience [1].
Learning and memory are closely related since it's only what has been learnt that can be remembered. Memory is the faculty of the mind by which information is encoded, stored and retrieved when needed. It is related to the limbic systems [2]. Often, memory is understood as an informational processing system with explicit and implicit functioning that is made up of sensory processor; short-term (or working) memory, and long-term memory [3].

Memory has three primary definitions; first, memory is 
the location where information is kept as in a store house or memory store. Second, memory can be referred to as anything that holds the contents of experience as in a memory trace or engram. Thirdly, memory is the mental process used to learn, store or retrieve information of all sorts [4]. In general, memory refers to the storage of information and the processes used to retrieve it.

Amitriptyline belongs to class of known as tricycline antidepresant (TCA) that is being used to treat anxiety and depressive states. Prolonged use of this drug causes tolerance and may lead to physical dependence on the drug [5,27]. Amitriptyline is reported to be metabolized by a hepatic enzyme belonging to the cytochrome P450 family of enzymes [6]. Much of the current knowledge of memory has come from studying memory disorders which can result from extensive damage to the regions of the medial temporary lobe [7]. Tricycline antidepresant, such as amitriptyline and which has a half-life of 10-50 hours with plasma concentration occurring approximately 1 hours after its oral administration [8], have been used in the pharmacological treatment of anxiety since the early 60's [9]. The Tricycline antidepresant family of depressants is used therapeutically to produce sedation, induce sleep, relieve anxiety and muscle spasms, and to prevent seizures. In general, they act as hypnotics in high doses, anxiolytics in moderate doses and sedatives in low doses. Their mechanism of action on the Central Nervous System is believed to be related to their ability to enhance the activity of gamma aminobutyric acid (GABA) which is a major inhibitory neurotransmitter [10-13]. Effects of oral doses of amitriptyline on memory, psychomotor activity, reaction time and vigilance performance have been widely demonstrated [14-18]. It has been observed that amitriptyline deteriorates the ability of the individual to detect relevant information in the environment [19-22].

\section{Materials and methods}

\section{Experimental animals}

Eighteen (18) mice weighing about 16-25 g were used for the study. The mice were kept under standard conditions in the animal house of the Department of Physiology, University of Calabar, Calabar. The mice were kept in plastic cages and were given free access to rodent chow and water. The animals were acclimatized under standard conditions and were kept in 12 hours light/dark cycle for 7 days before conducting the experiment. This was done in order to enable the animals get familiar with the new environment.

\section{Experimental protocol}

The 18 mice were randomly selected and assigned into three groups. Group 1 was used as control group, Group 2 was amitriptyline group treated at a dose of $3 \mathrm{mg} / \mathrm{kg}$ body weight dissolved in $3 \mathrm{mls}$ of distilled water to demonstrate for learning (used to test for learning). Group 3 was also treated with amitriptyline just like the group 2 (used to test for memory).
Each group (ie Group 1 (control), Group 2 (amitriptyline on learning), and Group 3 (amitriptyline on memory) had six (6) mice, making a total of eighteen (18) mice that were used for this study. The administration was carried out between 9 am 11 am each day and lasted for a period of 14 days. During this period, the animals were tested with Novel Object Recognition Task (NORT) and Morris Water Maze (MWM) to compare the effect of amitriptyline on learning and on memory.

\section{Novel Object Recognition Task (NORT)}

The NORT evaluates the animals' ability to recognize a novel object in the environment. Prior to testing, all mice were habituated to the apparatus for 5-minutes before hand. The mice were carried to the test room in their home cages and run individually. They were moved from their home cage to the testing apparatus and back using a small container. After each 5-minutes trial, the mice were returned to their home cages and the apparatus was cleaned with methylated spirit and permitted to dry between trials. Two pairs of identical objects were used. Two trials (acquisition and recognition) were conducted on the same day, separated by a retention period of 5-minutes during the first trial, two identical objects (01 and 02) were placed in diagonal corners opposite each other in the open field. Objects were secured to the floor of the apparatus with reusable adhesive. The mouse was scooped up from its home cage in a yogurt container and placed in the middle of the open field arena. Each mouse was allowed to explore the arena and objects for 5-min. At the end of the trial the mouse was removed from the apparatus using the yogurt container and returned to its home cage. After a 5-minutes inter-trial interval (retention period) the mouse was returned to the test apparatus (trial 2). The arena now contained the familiar object ( 01 or 02 from trial 1 ) in one of the two locations in trial 1 and a new object $(\mathrm{N})$ that replaces 01 or 02 . The same behaviors recorded for trial 1 were recorded for 5-min for trial 2.

1. The behaviors scored using the Open field [23] include:Line Crossing: frequency with which the mouse crossed one of the grid lines with all four paws.

2. Rearing: frequency with which the mouse stood on their hind legs in the maze.

3. Rearing Against a Wall: frequency with which the mouse stood on their hind legs against a wall of the open field.

4. Stretch Attend Postures: frequency with which the animal demonstrated forward elongation of the head and shoulders followed by retraction to the original position.

5. Grooming: frequency and duration of time the animal spent licking or scratching itself while stationery.

6. Approaches to each object: directing the nose to the 
object at a distance of $<1 \mathrm{~cm}$ and/or touching it with the nose.

7. Time spent with Each Object: Sniffing or climbing the object. Sitting on the object is not considered as an exploratory behavior.

\section{Morris Water Maze (MWM)}

The Morris water maze that was used for the study was modified for mice [24]. Morris water maze is constructed from a circular polypropylene pool that measures $110 \mathrm{~cm}$ in diameter and $20 \mathrm{~cm}$ in depth. The pool was filled to the depth of $140 \mathrm{~cm}(0.5 \mathrm{~cm}$ over the escape platform). The water was left 24 hours to assume room temperature and was made opaque by the addition of a non-toxic chalk. The pool was divided into four quadrants; North-West, North-East, South-East, and South-West. Boundaries of the quadrant were marked on the edges of the pool with masking tape and labeled north, south, east and west. An escape platform made of a cylinder $(13.5 \mathrm{~cm} \times 9 \mathrm{~cm})$ in diameter filled with cement to make firm was suspended and hidden $0.5 \mathrm{~cm}$ beneath the pool. The MWM is an experimental test protocol that lasted for eight days as follows:

\begin{tabular}{|c|c|c|}
\hline Day 1 & - & Acquisition day 1 \\
\hline Day 2 & - & Acquisition day 2 \\
\hline Day 3 & - & Acquisition day 3 \\
\hline Day 4 & - & Reversal day 1 \\
\hline Day 5 & - & Reversal day 2 \\
\hline Day 6 & - & Reversal day3 \\
\hline Day 7 & - & Probe trial day \\
\hline Day 8 & - & Visible platform day \\
\hline
\end{tabular}

Acquisition and Reversal trainings were done with the escape platform hidden $0.5 \mathrm{~cm}$ below the opaque water (in the North-East quadrant during acquisition training and the South-west quadrant during the reversal training). During the probe trial, there was no escape platform so that visuospatial memory can be assessed. On the visible platform day, the platform was moved to another quadrant of the pool and a visible top is added to the platform. During the acquisition training (Day 1 - 3), the platform was placed (and hidden $0.5 \mathrm{~cm}$ below) in the centre of the North east quadrant. Each mouse was given a maximum of 60 seconds to locate the hidden platform within the allotted time. It was then allowed at least 10 seconds on the platform to view extra maze cues after which it was removed from the pool using a small container and the swim latency (i.e the time it took the animal to locate and climb the escape platform was recorded. If the animals could not locate the platform after 60 seconds then it is directed to the platform using a small container and allowed for 10 seconds before it is taken out of the pool. It is important that all the animals be removed from the pool only after they may have climbed the escape platform so as to let the animals associate climbing of the platform with escape from the pool. When the animal is removed from the pool, it is usually placed in a holding cage where their body is dried using tissue before being returned to their home cages. During the reversal training (day $4-6$ ), the location of the escape platform was changed to the south-west quadrant. The mouse was again assigned appropriate start locations and the same procedure as in acquisition training was repeated. On the probe trial day (day 7), visuo-spatial memory status of all the animals were accessed on this day, the platform was taken out of the pool. All the animals received only one trial from any one of all the four start locations (from the North pole) and allowed to explore the maze for 60 seconds. Here, the quadrant duration (i.e the number of times the animals spent on each quadrant) was recorded. At the completion of the trials, the animals were then scooped out of the maze using a small container and placed in its appropriate holding cage to dry and then returned to their home cages. It is believed that animals with good visuo-spatial memory will spend more time in the quadrants where the escape platform was located. On the visible platform day (day 8), the platform is placed in a new quadrant or location (north-west quadrant) but this time made visible through the attachment of a colorful detachable flag to the top of the platform. The same procedure as in acquisition and reversal training were repeated as each of the animals received and completed four trials.

\section{Statistical analysis}

Data obtained from the study was expressed as mean \pm SEM following one-way analysis of variance (ANOVA) and statistical comparison among the groups was performed with Turkey multiple comparison test using SPSS, version 17. 0. $p<0.05$ was considered statistically significant

\section{Results}

\section{Comparison of total object approaches during the acquisition and retention trials of the novel object recognition task in mice treated with Amitriptyline}

The mean \pm SEM of total approach trial 1 during the acquisition trials of the novel object recognition task in control, amitriptyline groups were $16.8 \pm 1.38$ and $17.9 \pm 1.52$ respectively while the mean \pm SEM of total approach trial 2 during the retention trial of the novel object recognition task in control, amitriptyline groups were $12.2 \pm 0.75$, and $14.3 \pm 1.01$ respectively. There was a significant decrease $(p<0.05)$ in retention trial of the control and amitriptyline groups when compared to their acquisition trial. There was a significant increase $(p<0.05)$ in acquisition trial of amitriptyline when compared to the acquisition trial of control group. There was a significant decrease $(p<0.05)$ in acquisition trial of amitriptyline group when compared to the acquisition trial of control group. There was a significant increase $(p<0.05)$ in retention trial of amitriptyline group when compared to the retention trial of the control group. There was a significant decrease $(p<0.05)$ in retention trial of amitriptyline group when compared to the retention trial of control group (Figure1). 
Comparison of total duration (sec) of exploring objects during the acquisition and retention trials of the novel object recognition task in mice treated with Amitriptyline

The mean \pm SEM of total duration trial 1 of control, amitriptyline groups were $38.23 \pm 2.04$, and $31.4 \pm 2.68$ respectively while the mean \pm SEM of total duration of trial 2 of control and amitriptyline groups were $28.7 \pm 2.58$ and $55.6 \pm 8.87$ respectively. There was a significant decrease $(p<0.05)$ in retention trial of the control group when compared to its acquisition trial. There was a significant increase $(p<0.05)$ in acquisition trial of the amitriptyline group when compared to the acquisition trial of the control group. There was a significant decrease $(p<0.05)$ in acquisition trial of amitriptyline group when compared to the acquisition trial of the control group. There was a significant increase $(p<0.05)$ in retention trial of amitriptyline when compared to the retention trial of the control group. There was a significant decrease $(p<0.05)$ in retention trial of amitriptyline group when compared to the control group (Figure 2).

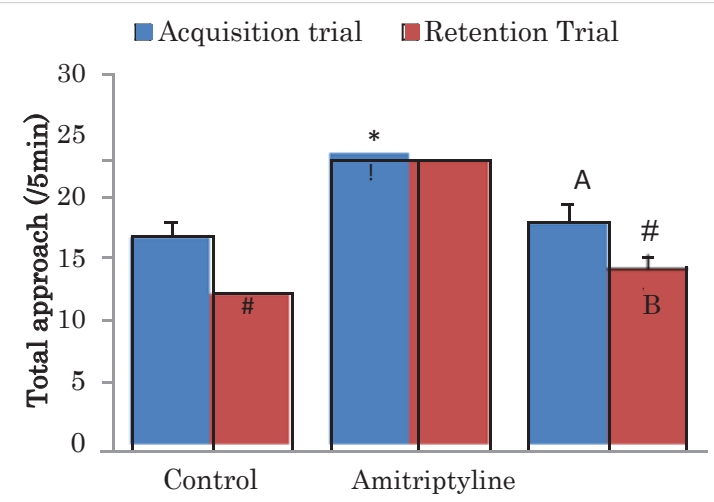

Figure 1: Comparison of total object approaches during the acquisition and retention trials of the novel object recognition task in mice treated with Amitriptyline Values are mean \pm SEM, $n=6$.

"significant at $p<0.05 \mathrm{vs}$. acquisition trial; *significant at $p<0.05 \mathrm{vs}$. control during the acquisition trial;

a-significant at $p<0.05$ vs. amitriptyline group during the acquisition trial; !-significant at $p<0.05$ vs control during retention trial;

b-significant at $p<0.05$ vs. amitriptyline group during retention trial.

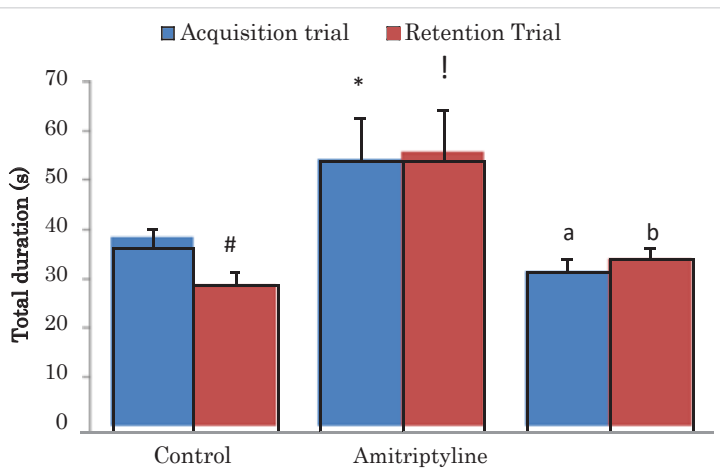

Figure 2: Comparison of total duration exploring objects during the acquisition and retention trials of the novel object recognition task in mice treated with amitriptyline Values are mean \pm SEM, $n=6$.

"significant at $p<0.05$ vs. acquisition trial; *significant at $p<0.05$ vs. control during the acquisition trial;

a-significant at $p<0.05$ vs. amitriptyline group during the acquisition trial; !- significant at $p<0.05$ vs. control during retention trial;

b-significant at $p<0.05$ vs. amitriptyline group during retention trial.
Comparison of index of habituation (h) in the novel object recognition task in mice treated with amitriptyline

The mean \pm SEM of habitation index of control, groups were $11.49 \pm 2.58$ and amitriptyline $292.6 \pm 1.85$ respectively. There was a significant decrease $(p<0.01)$ in $\mathrm{H}$ in amitriptyline group when compared to the control group. There was also a significant decrease $(p<0.05)$ in $\mathrm{H}$, in amitriptyline group when compared to control group (Figure 3).

Comparison of index of discrimination (d) in novel object recognition task in mice treated with amitriptyline

The mean \pm SEM of $D$ for control, amitriptyline groups were $0.36 \pm 0.06$ and $19 \pm 0.45$ respectively. There was a significant decrease $(p<0.05)$ in D amitriptyline group when compared to the control group. There was a significant decrease $(p<0.01)$ in D amitriptyline when compared to the control group. There was a significant increase $(p<0.05)$ in D amitriptyline group when compared to the control group (Figure. 4).

\section{Learning curves showing comparison of swim latencies during acquisition training of Morris Water Maze (MWM) test in mice treated with amitriptyline}

The mean \pm SEM of swim latencies values (secs) during acquisition training in day 1 for control amitriptyline groups were $48.8 \pm 1.91$ and $55.7 \pm 1.27$ respectively. The mean \pm SEM of swim latencies values (secs) during acquisition training in day 2 for control and amitriptyline groups were $42.65 \pm 3.89$ and $50.9 \pm 1.83$ respectively. There was no significant difference

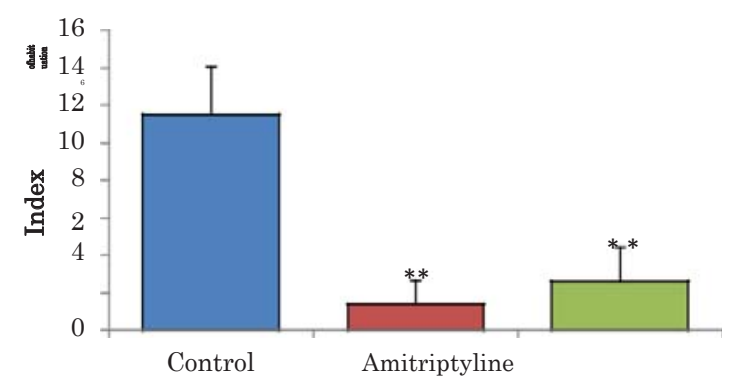

Figure 3: Comparison of index of habituation in the novel object recognition task in mice treated with amitriptyline. Values are mean \pm SEM, $n=6$. ${ }^{* *}$ significant at $p<0.01 \mathrm{vs}$. control.

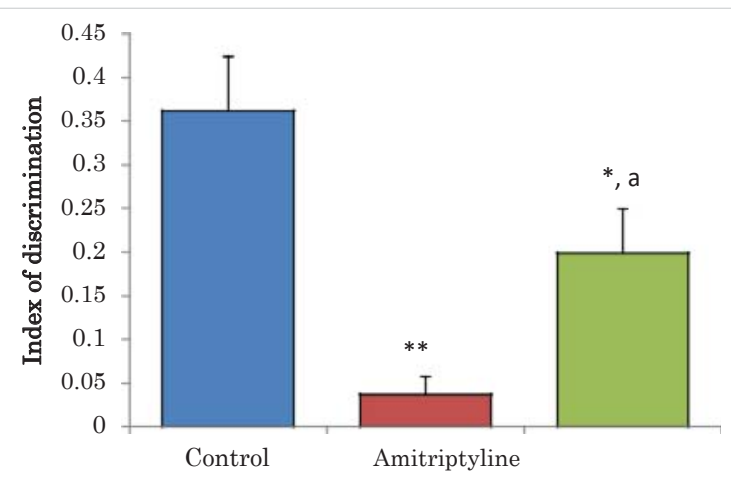

Figure 4: Comparison of index of discrimination in the novel object recognition task in mice treated with amitriptyline. Values are mean $\pm \mathrm{SEM}, n=6$.

${ }^{*}$ significant at $p<0.05$ vs. control; ${ }^{* *}$ significant at $p<0.01$ vs. control, a-significant at $p<0.05$ vs. amitriptyline group of mice. 
in swim latencies in day 1 and 2 among the group. The mean \pm SEM of swim latencies values (secs) during acquisition training in day 3 in control and amitriptyline groups were $37.3 \pm 1.61$ and $43.7 \pm 3.40$ respectively. However, there was a significant decrease $(p<0.05)$ in amitriptyline group when compared to the control group and there was also a significant decrease $(p<0.05)$ in amitriptyline group when compared to control group (Figure 5).

Learning curves showing comparison of swim latencies during the reversal training of the Morris Water Maze test in mice treated with amitriptyline

The mean \pm SEM of swim latencies values (secs) during reversal training in day 1 for control and amitriptyline groups were $32.15 \pm 4.49$ and $37.25 \pm 1.29$ respectively. The mean \pm SEM of swim latencies values (secs) during reversal training in day 2 for control and amitriptyline groups were $27.25 \pm 7.56$ and $30.1 \pm 3.02$ respectively. The mean \pm SEM of swim latencies values (secs) during reversal training in day 3 for control, groups were $20.45 \pm 8.06,16.3$ and amitriptyline $22.3 \pm 4.16$ respectively. There was no significant difference in swim latencies during the reversal training in day 1, 2 and 3 among the groups (Figure 6).

Comparison of swim latencies in the visible platform task of the morris water maze test in mice treated with amitriptyline

The mean \pm SEM of retention quadrant duration in the

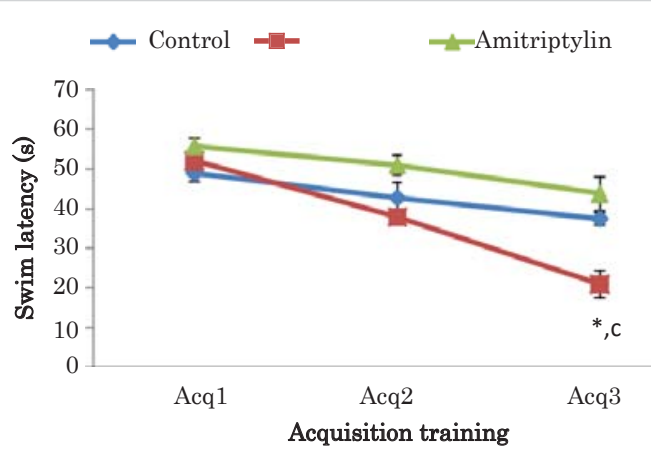

Figure 5: Learning curves showing comparison of swim latencies during the acquisition training of the Morris water maze test in mice treated with amitriptyline Values are mean \pm SEM, $n=6$. *significant at $p<0.05$ vs. control; $\mathrm{c}$-significant at $p<0.05 \mathrm{vs}$. amitriptyline group of mice.

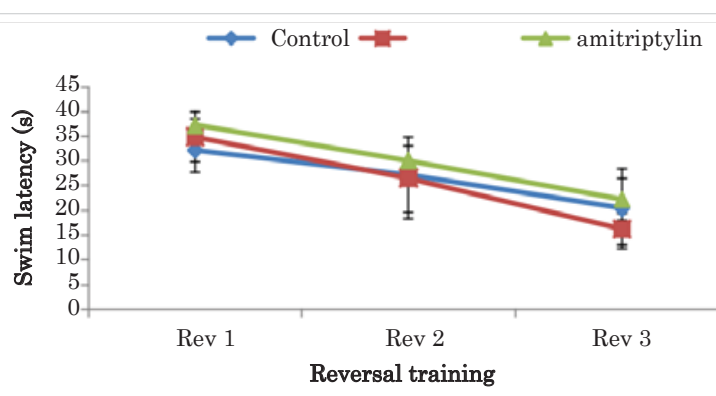

Figure 6: Learning curves showing comparison of swim latencies during the reversal training of the Morris water maze test in mice amitriptyline Values are mean \pm SEM, $n=6$. probe trial of the Morris water maze in control groups and amitriptyline were $35.6 \pm 0.50$ and $26.5 \pm 2.62$ respectively there was a significant decrease $(p<0.01)$ in amitriptyline group when compared to the control group (Figure 7).

Comparison of swim latencies in the visible platform task of the Morris water maze test in mice treated with amitriptyline

The mean \pm SEM of swim latencies values (secs) in the visible platform task of the Morris water maze test in control and amitriptyline groups were $22.15 \pm 5.27$ and $32.33 \pm 4.78$ respectively. There was no significant difference among the groups (Figure 8).

\section{Discussion}

\section{Novel Object Recognition Task (NORT)}

Comparing the total object approaches and duration during the acquisition and retention trials of the novel object recognition task, it was observed that the amitriptyline treated group approached less frequently and spent less time with the novel object than the familiar one compared to the control group. When animals are exposed to a familiar and a novel object, they approach frequently and spend more time exploring the novel than the familiar one [25]. Thus, it is pertinent to say that the control group learnt better than the amitriptyline group and this could be as a result of the adverse effect of amitriptyline on the central nervous system

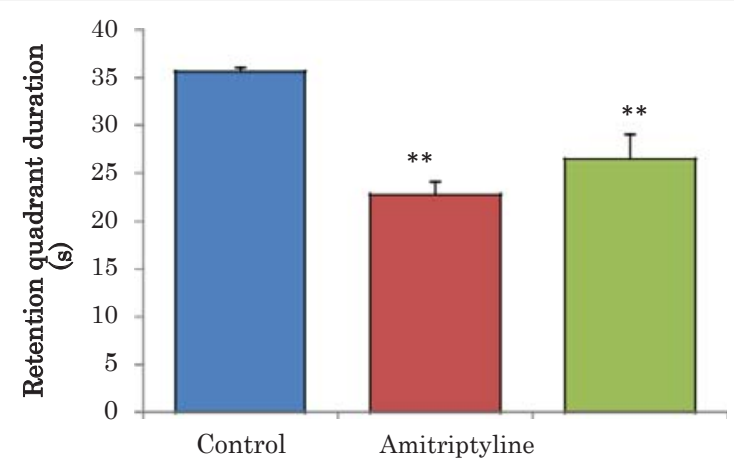

Figure 7: Comparison of retention quadrant duration in the probe trial of the Morris water maze test in mice treated with amitriptyline. Values are mean $\pm \mathrm{SEM}, n=6$. ${ }^{* *}$ significant at $p<0.01$ vs. control.

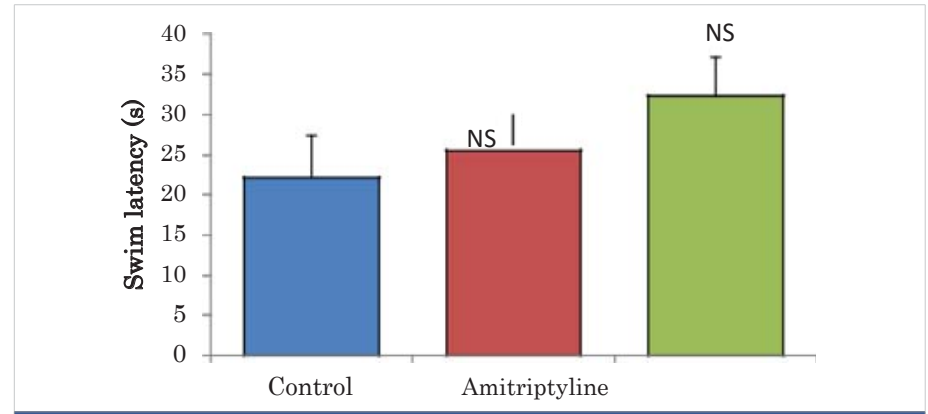

Figure 8: Comparison of swim latencies in the visible platform task of the Morris water maze test in mice treated with amitriptyline Values are mean $\pm \mathrm{SEM}, n=6$. NS: Not Significant vs. control. 
[16]. When comparing the index of habituation which is the decrease of a response to a repeated eliciting stimulus, it was observed that amitriptyline treated group had a lower habituation index compared to the control group. This suggests that the control group had a better learning and memory than the amitriptyline group [26]. Comparing the discrimination index, which is a measure of item quality whenever the purpose of a test is to produce a spread of scores reflecting differences in achievement, so that distinctions may be made among the performances, amitriptyline treated group had a lower discrimination index compared to the control group. This implies that amitriptyline treated group learned less when compared to the control group.

\section{Morris water maze}

The results obtained from the test showed that during the acquisition trial which lasted for three (3) days, the swim latency was longer in amitriptyline treated group when compared to the control group. The amitriptyline treated group had a shorter swim latency compared to the control group. The control group showed a stronger relationship between the number of trials and the swim latencies. This is because the shorter the swim latency, the better the learning and memory processes. During the reversal trainings, there was no significant difference among the two (2) groups of mice. During the probe trial day i.e. day seven (7), there was a significant decrease in retention quadrant duration of amitriptyline group compared to the control group. This suggests that there was a significant decrease in learning and memory in amitriptyline group when compared to the control group. The visible platform expresses the visual abilities of the animals. On day eight (8) which was to compare visible platform, there was no significant difference between the groups. This suggests that two (2) groups had almost equal visual acuity.

\section{Conclusion}

Results from the study suggest that, at the dose given which was $3 \mathrm{mg} / \mathrm{kg}$ body weight, amitriptyline impaired learning and memory functions significantly by reducing the capacity for discrimination and retention in the amitriptyline treated groups.

However, the mechanisms by which amitriptyline impact these effects is not yet fully unknown, and may require further findings.

\section{Ethicalclearance}

The Name of the Ethic Committee that approved our work is: "University of Calabar Faculty of Medical Sciences Ethics Committee on Animals Experiments". The reference/approval number for the research work is: UCFMSECAE1086.

\section{Declaration}

This work did not receive any form of Funding or financial support whatsoever from anyone. It is solely the personal efforts of the authors. It also did not receive any form of nonfinancial support from anyone. The Authors therefore owe no one any form of acknowledgement for the work.

\section{References}

1. Atkinson RC, Shiffrin RM. Chapter: Human Memory: A proposed system and its control processes. In Spence, K. W.; Spenc J. T. The psychology of learning and motivation 2 New York Academic Press. 1968; 89-105.

2. Eysenck A. Fundamentals of cognition. New York: Psychology Press 2007; 16-19

3. Baddely A. Working memory, thought and action. Oxford, UK: Oxford University Press 2007; 30-35.

4. Spear NE, Riccio DC. Memory: Phenomena and principles. Allyn and Bacconprintrs. 1994; 15-17.

5. Montenegro $M$, Veiga $H$, Deslandes A. Nuromodulatory effects of caffeine and bromazepam on visual event-related potential (P300): a comparative study. Arq Neuropsiquiaatr. 2005; 63: 410-415. PubMed: https://pubmed.ncbi.nlm.nih.gov/16059590/

6. Cunha M, Portela C, Bastos VH. Responsiveness of sensorimotor cortex during pharmacological intervention with bromazepam Neuroscience Letter 2008; 448: 33-36.

PubMed: https://pubmed.ncbi.nlm.nih.gov/18938214/

7. Zola M, Suire LR. Neuroantomy of memory. Ann Neurosci. 1993; 16 : 547-563.

PubMed: https://pubmed.ncbi.nlm.nih.gov/8460903/

8. Kaplan SA, Jack ML, Weinfeld RE, Glover W, Weissman L, et al Biopharmaceutical and clinical pharmacokinetic profile of bromazepam. J Phamacokinet Biopharm 2008; 4: 1-16.

PubMed: https://pubmed.ncbi.nlm.nih.gov/5586/

9. Graeff FG. Drogas psicotrópicas e seu modo de ação. 2.Ed. São Paulo: EPU, 1989.

10. Katzung BG. Basic clinical pharmacology. 6.Ed. London: PretenceHall, 1995; 40-47.

11. Oelschlager H. Chemical and pharmacologic aspects of benzodiazepines. Schweiz Rundsch Med Prax. 1989; 78: 766-772. PubMed: https://pubmed.ncbi.nlm.nih.gov/2570451/

12. Ennaceur A. One-trial object recognition in rats and mice: methodological and theoretical issues. Behav Brain Ress. 2010; 215: 244-254. PubMed: https://pubmed.ncbi.nlm.nih.gov/20060020/

13. Kopp C, Rudolph U, Low K, Tobler I. Modulation of rhythmic brain activity by diazepam: GABA (A) receptor subtype and state specificity. Proc Natl Acad Sci USA. 2004; 101: 3674-3679. PubMed: https://pubmed.ncbi.nlm.nih.gov/14990800/

14. Hobi V, Dubach UC, Skreta M, Forgo I, Riggenbach H. The subacute effect of bromazepam on psychomotor activity and subjective mood. J Intern Med Res. 1982; 10: 140-146.

PubMed: https://pubmed.ncbi.nlm.nih.gov/6124470/

15. Jansen AAI, Verbaten MN, Slangen JL. Acute effects of bromazepam on signal detection performance digit symbol substitution test and smooth pursuit eye movement. Nueropsychobiol. 1988; 20: 91-95. PubMed: https://pubmed.ncbi.nlm.nih.gov/2908134/

16. Heloisa VD, Andrea CD, Kaleb MC, Fernando AM. Neuromodulatory effects of caffeine and bromazepam on visual event related potential (P300): A comparative study. Arq Neuropsiquatar. 2005; 63: 410-415. PubMed: https://pubmed.ncbi.nlm.nih.gov/16059590/

17. Bourin M, Auget JL, Colombel MC, Larousse C. Effects of single ora doses of bromazepam, buspirone and clobazam on performance tasks and memory. Pharmacopsych. 1989; 22: 141-145. PubMed: https://pubmed.ncbi.nlm.nih.gov/2577220/ 
18. Koelega HS. Benzodiazepines and vigilance performance: a review. Psychopharmacology. 1989; 98: 145-156.

PubMed: https://pubmed.ncbi.nlm.nih.gov/2569213/

19. Van Leeuwen TH, Verbaten MN, Koelega HS, Kenemans JL, Slangen JL. Effects of bromazepam on single-trial event-related potentials in a visual vigilance task. Psychopharmacol 1992; 106: 555-564.

PubMed: https://pubmed.ncbi.nlm.nih.gov/1579628/

20. Polich J. P300 in clinical applications. In Niedermeyer E, Lopes da Silva F. (eds). Electroencephalography: basic principles, clinical applications and related fields. 4 Ed. Baltimore: Urban \& Schwarzenberg. 1999: 1073-1091.

21. Matthews A, Kirkby KC, Martin F. The effects of single-dose lorazepam on the memory and behavioural learning. J Psychopharmacol. 2002; 16: 345-354.

PubMed: https://pubmed.ncbi.nlm.nih.gov/12503834/

22. Hayakkawa T, Uchiyama M, Urata J. Effects of small dose of triazolam on P300. Psychiatry Clin Neurosci. 1999; 53: 185-187. PubMed: https://pubmed.ncbi.nlm.nih.gov/10459684/

23. Richard EB, Lianne S, Heather M. Developing standardized behavioural tests for knockout and mutant mice. ILAR J. 2000; 41: 163-174. PubMed: https://pubmed.ncbi.nlm.nih.gov/11406708/

24. Paylor R, Baskall-Baldini L, Yuva L, Wehner JM. Developmental differences in place-learning performance between C57BL/6 and $\mathrm{DBA} / 2$ mice parallel the ontogeny of hippocampal protein kinase $\mathrm{C}$. Behavio Neurosci. 1996; 110: 1415-1425.

PubMed: https://pubmed.ncbi.nlm.nih.gov/8986342/

25. Authier N, Balayssac D, Sautereau M, Zangarelli A. Benzodiazepine dependence: focus on withdrawal syndrome. Ann Pharm Fr. 2009; 67: 408-413.

PubMed: https://pubmed.ncbi.nlm.nih.gov/19900604/

26. Liljequist R, Linnoila M, Mattila MJ, Saario I. Effect of two weeks' treatment with thioridazine, chlorpromazine, sulphiride and bromazepam, alone or in combination with alcohol, on learning and memory in man. Psychopharmacologia. 1975; 44205-4208.

PubMed: https://pubmed.ncbi.nlm.nih.gov/710/

27. Umaharan T, Sivayokan S, Sivansuthan S. Amitriptyline Dependence and Its Associations: A Case Report and Literature. Review Case Rep Psychiatry. 2021; 2021: 6647952.

PubMed: https://pubmed.ncbi.nlm.nih.gov/33564485/ 